\title{
Endoscopic ultrasonography-guided fine-needle biopsy from the pancreatic head of a patient with Roux-en-Y reconstruction
}

Although endoscopic ultrasonographyguided fine needle biopsy (EUS-FNB) has been developed, its implementation is still challenging in patients with surgically altered anatomy [1-3]. A 68-yearold man who had undergone laparoscopic total gastrectomy with Roux-en$\mathrm{Y}$ reconstruction for gastric cancer 40 months previously was admitted to our department. His serum carcinoembryonic antigen (CEA) level was increased at $43.6 \mathrm{ng} / \mathrm{mL}$. Abdominal computed tomography (CT) scanning revealed an obscure mass beside the pancreatic head ( Fig.1a). An 18F-fluorodeoxyglucose positron emission tomography/CT scan revealed abdominal accumulation of tu-

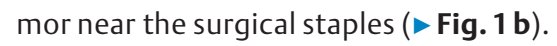
The patient underwent transjejunal EUSFNB. First, a double-balloon endoscope (DBE; El-530B; Fujifilm, Tokyo, Japan) was inserted into the afferent limb. Next, a 0.035-inch ultrastiff guidewire (Wrangler SUS endoscopic guidewire; Piolax Medical Devices, Yokohama, Japan) was placed in the afferent limb. Thereafter, a new curved linear echoendoscope (CLE; EG-580UT; Fujifilm) was inserted into the afferent limb over the guidewire under fluoroscopic and endoscopic guidance. The trajectory of the CLE was close to the surgical staples, these being a tumor landmark (-Fig. 2 ; V Video 1). The EUS revealed a hypoechoic mass beside the pancreatic head near the surgical staples. Finally, EUS-FNB was performed using a 22-gauge Franseen needle (Acquire; Boston Scientific Japan, Tokyo, Japan) without any complications ( Fig.3; - Video 1). The cytopathological diagnosis showed adenocarcinoma, consistent with recurrence of the gastric cancer.

EUS-FNB for patients who have undergone Roux-en-Y reconstruction, particularly from the pancreatic head, is still challenging [1-3]. The following tips have been illustrated by this case: (i) DBE-guided ultrastiff guidewire placement can correct flexion of the afferent

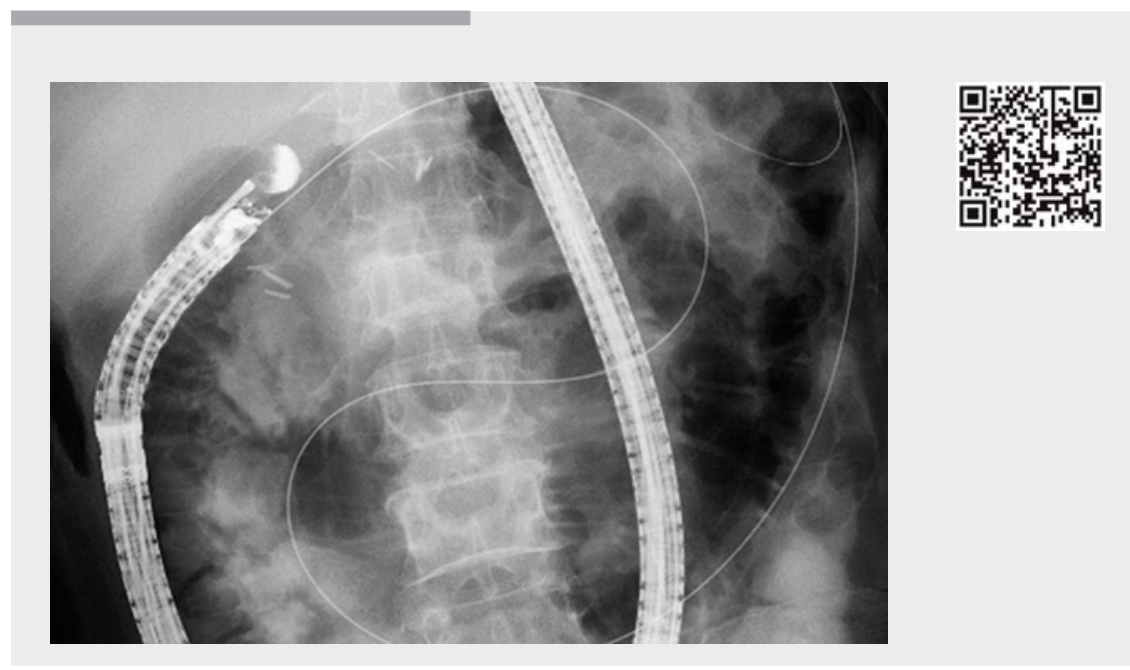

$\checkmark$ Video 1 Step-by-step process of endoscopic ultrasonography-guided fine needle biopsy of the pancreatic head through the afferent limb in a patient who had undergone previous Roux-en-Y reconstruction.
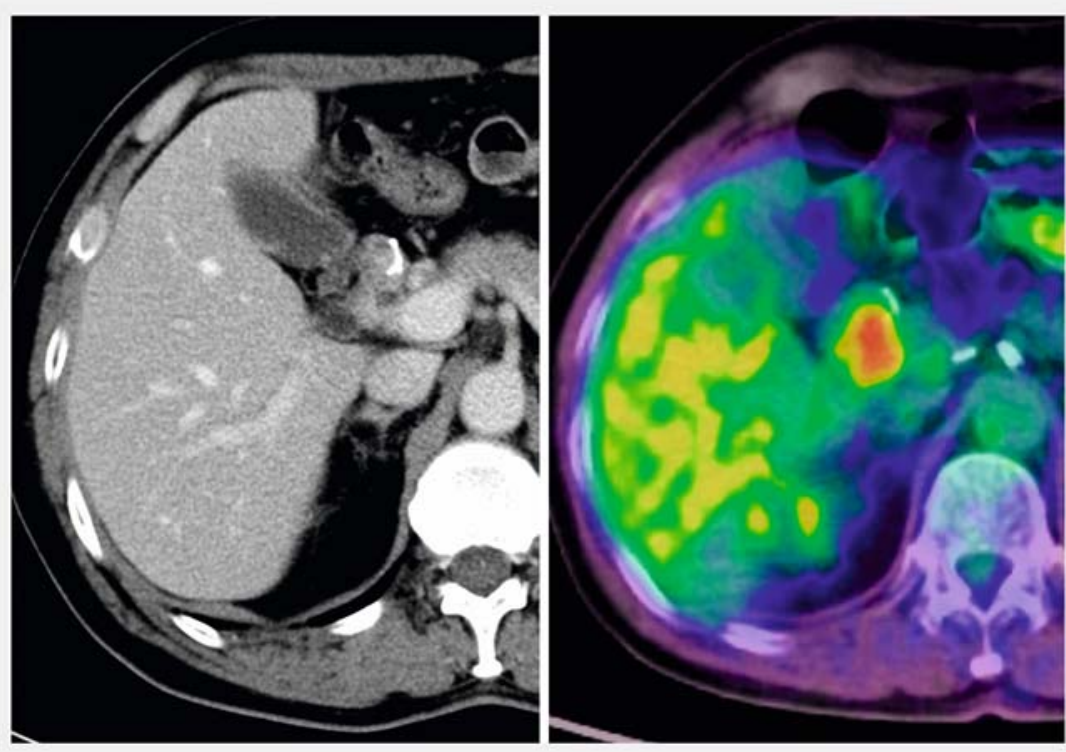

- Fig. 1 Images of a tumor mass near to the surgical staples in a patient who had undergone laparoscopic total gastrectomy with Roux-en-Y reconstruction: a contrast-enhanced computed tomography (CT) scan, showing an obscure mass beside the pancreatic head; $\mathbf{b}$ positron emission tomography (PET)/CT scan, showing an appearance suggestive of pancreatic cancer or a recurrent gastric cancer. 

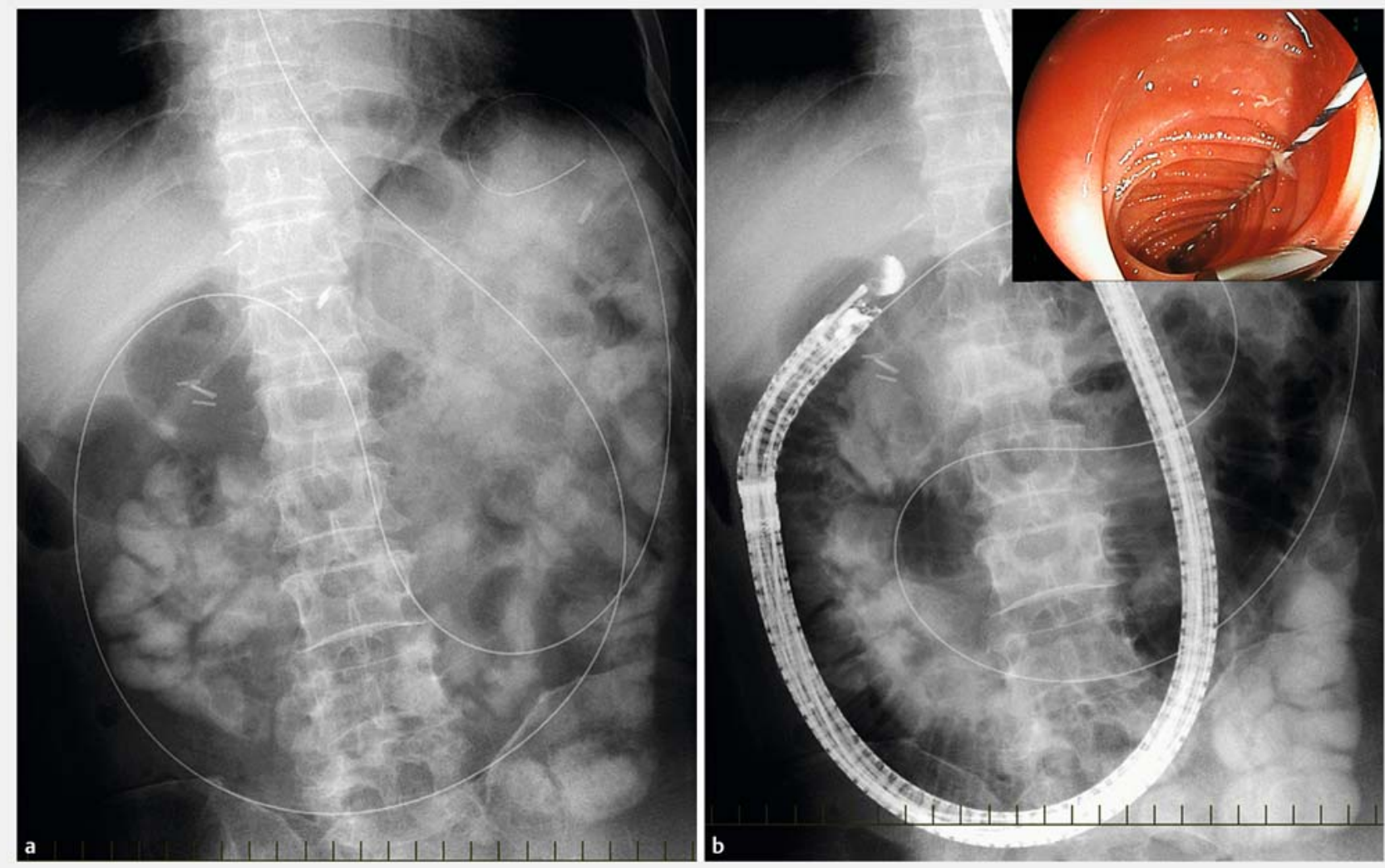

Fig. 2 Fluoroscopic images showing: a the ultrastiff guidewire placed in the afferent loop following double-balloon endoscope intubation; b the new curved linear echoendoscope that has been positioned following the guidewire and advanced near to the surgical staples. Inset: The tip of the echoendoscope is visualized endoscopically throughout the procedure.

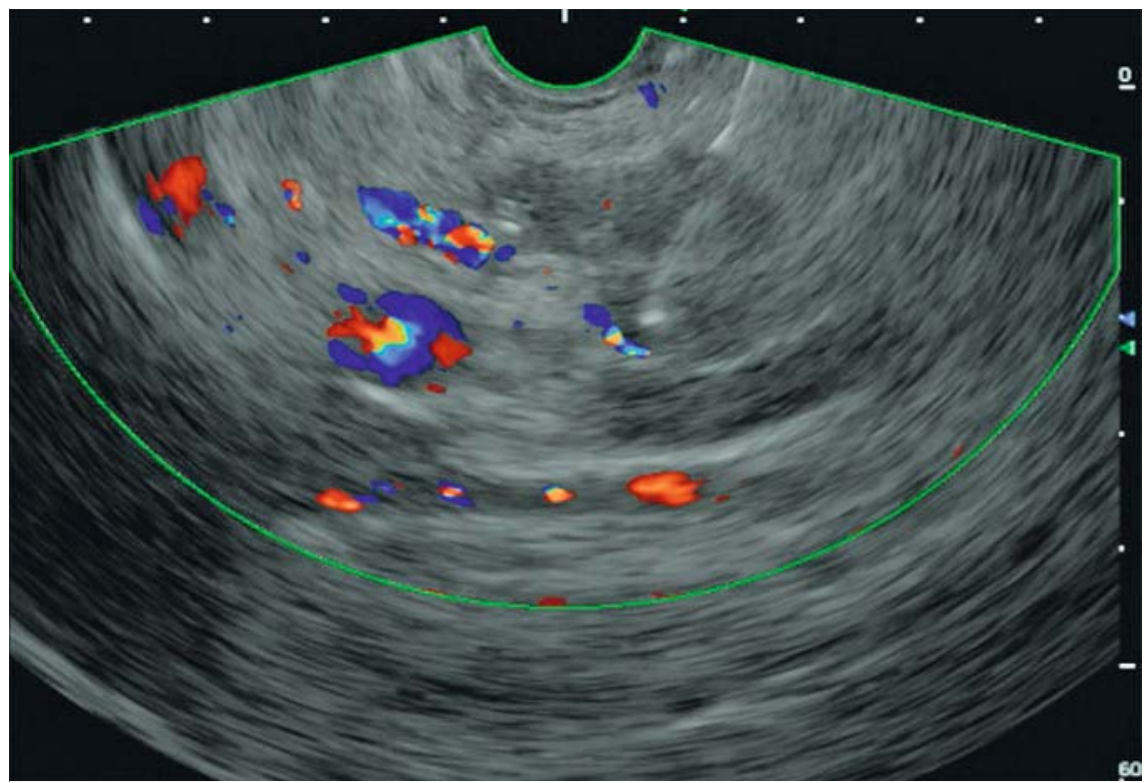

limbs; (ii) a new CLE enables safe and reliable intubation into the afferent limb because of the frontal endoscopic view and flexible scope tip [3]. The combination of DBE-assisted ultrastiff guidewire placement and new CLE intubation facilitates EUS-FNB from the pancreatic head for patients with surgically altered anatomy.

Endoscopy_UCTN_Code_TTT_1AS_2AF

Competing interests

\section{None}

Fig. 3 Echoendoscopic color Doppler image showing the 22-gauge Franseen biopsy needle beside the pancreatic head puncturing the hypoechoic mass, which was $18.2 \mathrm{~mm}$ in diameter. The image of the pancreatic head including the vascular system is similar to that obtained during an ordinary echoendoscopy at the duodenal bulb. 
The authors

Tesshin Ban ${ }^{1,2}$, Hiroshi Kawakami ${ }^{1,2}$, Yoshimasa Kubota ${ }^{1,2}$, Shinya Ashizuka², Kazusato Oshikawa

1 Department of Gastroenterology and Hepatology, Faculty of Medicine, University of Miyazaki, Miyazaki, Japan

2 Department of Gastroenterology and Hepatology, Division of Endoscopy, and Center for Digestive Disease, University of Miyazaki Hospital, Miyazaki, Japan

Corresponding author

Hiroshi Kawakami, MD, PhD

5200 Kihara, Kiyotake, Miyazaki, Miyazaki 889-9602, Japan

Fax: +81-985-859802

hiropon@med.miyazaki-u.ac.jp

\section{References}

[1] Wilson JA, Hoffman B, Hawes RH et al. EUS in patients with surgically altered upper $\mathrm{Gl}$ anatomy. Gastrointest Endosc 2010; 72: 947-953

[2] Jeon MK, So H, Park DH. Fluoroscopicassisted, EUS-guided trans-sigmoidal pancreas biopsy in a patient with surgically altered anatomy. Am J Gastroenterol 2017; 112: 1637

[3] Kawakami H, Kubota Y. New curved linear echoendoscope for endoscopic ultrasonography-guided fine-needle aspiration in patients with Roux-en-Y reconstruction (with videos). Endosc Ultrasound 2018; 7: 128 129

\section{Bibliography}

DOI https://doi.org/10.1055/a-0624-1319

Published online: 12.6.2018

Endoscopy 2018; 50: E202-E204

(c) Georg Thieme Verlag KC

Stuttgart · New York

ISSN 0013-726X
ENDOSCOPY E-VIDEOS

https://eref.thieme.de/e-videos

回局 Endoscopy E-Videos is a free access online section, reporting 田: on interesting cases and new techniques in gastroenterological endoscopy. All papers include a high quality video and all contributions are freely accessible online.

This section has its own submission website at https://mc.manuscriptcentral.com/e-videos 